\title{
The Local Explanatory Model: A Study of Assumed Causes of Tuberculosis in Rural Nepal
}

\section{Ulla-Britt Engelbrektsson Madhusudan Subedi}

\begin{abstract}
Tuberculosis (TB) constitutes one of the major public health problems in Nepal. Our theoretical framework, in this paper, is to explore people's understanding of the culturally constructed reality, the local explanatory model, for causes of Tuberculosis. The ethnographic data were collected from 'Solubang' village of Pyuthan district in 2005 and 2012/13. The finding shows that assumed and suggested cause(s) of TB are multiple but most often within a framework of great uncertainty. Compared to 2005, people were better aware of the need for timely treatment in 2012/13. The arrival of the biomedical anti-TB medicines has changed the situation for the better and is widely recognized but perception on causes of TB and its prevalence have not changed drastically, and mortality rates have not decreased at the speed hoped for.

Keywords: explanatory model, etiology, rural Nepal, tuberculosis, uncertainty
\end{abstract}

\section{Introduction}

Tuberculosis (TB) ranks as the second leading cause of death from an infectious disease worldwide. In 2013, an estimated 9.0 million people developed TB and 1.5 million died from the disease (WHO, 2014). The South-East Asian Region accounts for 38 percent of the global burden of TB in terms of incidence. It is estimated that about 
3.4 million new cases of TB occur each year and about 440,000 people died of this disease in 2013 (WHO, 2015).

TB constitutes one of the major public health problems in Nepal, causing a significant burden of morbidity and mortality. According to the latest report, about 45 percent of the total population is infected with TB, out of which 60 percent are adults. Every year 40,000 people develop active TB of whom 20,000 have infectious pulmonary TB. These 20,000 are able to spread the disease to others. TB causes estimated 5,000-7,000 deaths per year in Nepal (HERD, 2016). TB in Nepal deeply affects the lives of the patients and their families. Early diagnosis and initiation of appropriate treatment is the mainstay in the prevention and control of TB. Biomedically, TB is an infectious disease, in humans mainly caused by Mycobacterium tuberculosis. The disease usually affects the lungs (pulmonary TB) but can also occur in other parts of the body (extra-pulmonary TB). When a person with infectious TB coughs, sneezes, spits or talks, droplets containing TB bacteria are released into air. The main symptoms of pulmonary TB are: cough for two weeks or more; lowgrade fever; blood stained sputum; chest pain. The signs of extrapulmonary TB depend on the organ involved. Signs and symptoms common to both types are: loss of appetite; loss of weight; weakness of body. Presently, active drug-sensitive TB is treated with a standard six-month course of four antimicrobial drugs. Almost 95 per cent of the bacterial sterilization takes place within the first two weeks of the therapy (Dheda, 2010, p.17).

There are some studies on various aspects of TB in Nepal (Harper, 2006; Hatherall, 2009; Baral et al., 2007; Baral and BC, 2011; Bhatt et al., 2009, Bhatt et al., 2010). These studies found that the majority of the TB patients had satisfactory knowledge about the signs and symptoms but their knowledge about causative factors was low. This paper focuses on the local explanatory model of TB as perceived by patients, their family and community members. The ethnographic data were generated from one community in the Hill district of Pyuthan. Two major field-studies, each running over a month and an half, were carried out in the same community, in Solubang, the first in 2005 and the second in 2012/13. 


\section{Theoretical and Methodological Approach}

In studying societies and cultural groups and their health belief practices anthropologists use an ethnographic approach to see how the world looks from the perspective of the members of society. They live with, interact and observe a group of people and learn to see the world through their eyes and explore the meanings. In understanding bodily illness, it is useful to explore the types of questions that people ask themselves when they feel unwell, or when they experience any sudden, unexpected events in their daily lives (Subedi, 2001; Helman, 2007).

Illness causality can be identified and understood at different levels. Evans-Pritchard (1937) argues that belief in witchcraft does not necessarily contradict empirical knowledge of cause and effect. Witchcraft answers the question of "why" misfortune happens to a particular person but not necessarily "how" it happens. Salzberger (1976) proposes that the responsibility for an illness is ascribed either to the victim or to external factors. In the first group of hypotheses, the individual is made responsible for his/her choices, conscious or unconscious, and hence for his/her sickness. In the second group, the individual is thought of as a victim of chance or blind fate. Foster and Anderson (1978) differentiate between personalistic and naturalistic etiologies. A personalistic system is a system in which illness is believed to be caused by the active, purposeful intervention of a sensate agent, whereas a naturalistic system is a construction in which illness is explained in impersonal, systemic terms. They suggest that a combination of personalistic and naturalistic explanations is common in medical systems, but with one usually much favored over the other.

Our theoretical framework is to explore people's understanding of the culturally constructed reality. Kleinman (1980) has suggested a useful way of looking at the process by which illness is patterned, interpreted and treated, which he terms the Explanatory Model (EM). The EMs offer explanations for five aspects of illness: the etiology or causes of the condition, the timing and mode of onset of symptoms, the pathophysiological processes, the natural history and severity of the illness, and the appropriate treatment for the condition. The EMs tend to be 'idiosyncratic and changeable' (Kleinman, 1980; 
Helman, 2007; Subedi 2003; Subedi 2011). Kleinman (1980) points out that individuals are likely to have quite vague and indefinite models of explanations for their illnesses, depending on past experiences of the patients and his/her circle of kin and friends, and our findings also affirm his argument. Young (1992) adds that a wide array of fragmentary explanations from multiple sources and different knowledge structures may be used in the construction of lay illness narratives. Helman (2007) suggests that in most cases lay theories of illness etiologies are multi-causal, that is, they postulate that several causes act together. These cultural categories not only change through time, but they also can be differentially interpreted by people interacting within a web of relationships embedded in a larger material and social contexts (Trostle, 2005). In our view, exploration of local understanding of health and illness has considerable implication for areas of health and healing.

The study was conducted in Solubang, an agricultural village in the hill district of Pyuthan, in the Mid-Western Development Region, north of, but not far from, the district headquarters. The village is populated by several castes but with Chhetries in the numerical and political lead. Two major field-studies, each running over a month and an half, were carried out in the same community, in Solubang, the first in 2005 and the second in 2012/13.

At the time of the first study in 2005 , the population of Solubang amounted to just fewer than 800 persons in approximately 130 households, of which more than half were Brahmin and Chhetri households, about 10 percent Magars and the remaining 30 percent were Dalits. The housings were clustered caste-wise. Financially, most households had difficulties making ends meet. Only a quarter, it was said, had enough crops to last for a year. Thus, additional work had to be found. Some did so within the district as day laborers and in low-level government jobs and others in seasonal or long term labor in India. A few families had moved out but no one had moved in. Thus, it was a well-grounded population but with plenty of opportunities for influences from the outside.

The TB patients were found by asking around and by help of TB registers and treatment cards at local and nearby DOTS centres. The TB patients were found by asking around and by help of TB 
registers and treatment cards at local and nearby DOTS centres. In 2005, 24 Solubang TB patients from the preceding seven years were thus identified. In 2013, the same procedures resulted in 15 patients. In the two cohorts, altogether 26 males versus 13 females were covered. The caste distribution within the two cohorts reflected that of the village as a whole.

The patients were contacted and face-to-face interviews were conducted. For the TB cases of too young children guardians were interviewed. Besides the patients, at least one household member and one next-door neighbor of each patient were interviewed. There was a questionnaire in the form of an open-ended interview-guide for each category. One hundred twenty residents were thus formally interviewed. Moreover, there were observations and informal talks with other community members and with local health workers. In addition, in the second study there were follow-up interviews with the patients of the first study. Responses to the open-ended questions were analyzed thematically.

\section{Major Findings}

Before the availability of anti-TB medicines, TB was a much feared condition in Solubang, as in the rest of Nepal. The local denotation was 'khapte' a word used for half-rotten fruit (the other half also likely to rot) and/or 'sukenash' meaning thin or wasted. The condition was believed to be contagious, that is, transmittable to others. Those in advanced stages of the disease were put out of the house. When possible, they were placed under a pine tree as such trees were believed to have a soothing and perhaps even a healing influence, even so, most died within a short period of time. Later the medical Nepali term for tuberculosis, 'kshayarog' or 'chayarog' was adopted and still later the English abbreviation 'tibi' (TB).

\section{Perceived Causes of Tuberculosis in 2005}

In general when sick, the first choice outside the home was a consultation with a local healer (dhami/jhankri) of one's own caste, if that did not work a more powerful dhami/jhankri of any caste within or out of the village was likely to be approached. The dhami/ jhankri services ranged from free consultations by the roadside to 
night-long costly sessions with all the traditional paraphernalia. Some healing rituals included animal sacrifice. At the same time there were public government health facilities easily reachable with few hours of walk. Their services were well thought of but were usually not the first port of call. A main reason was the expected expenses, not for the consultation per se but for the many medicines prescribed. The same was true in regard to a recently opened private pharmacy in the district headquarters.

At the time of the first study, Solubang residents reckoned that the village had had more than its reasonable share of TB. The frequently suggested reason was that the alcohol consumption was high. In 2005, as mentioned, 24 TB patients were identified. Twenty-two of them (14 males, 8 females) were registered for treatment within the district, with somewhat less than half diagnosed as sputum-smear positive.

\section{The neighbours}

Most respondents answered well in regard to signs and symptoms of pulmonary TB. This was the case of an elderly man who said, "We know it is TB when someone starts to cough, bleed from the mouth, not feel like eating, have fever in the evening, and the person loses weight." A few added, "The face gets dark." Only one or two, referred to a sign or symptom specifically connected with extrapulmonary TB. Yet, 6 of the 24 patients in the cohort were registered as such.

In response to a general question about the causes of $\mathrm{TB}$, a few suggested that they had no idea about the cause(s) of TB, some mentioned one or two possibilities, but most proposed several ideas. A common denominator, however, was that the disease was "from the person's own body." Moreover, it was frequently stressed that it was from "a weak body", a body weakened by poverty, by lack of good food or regular eating, most often in connection with too much alcohol. One or two added that TB was likely to be "hereditary". "Germs" were mentioned by some but not emphasized. Child-TB was not referred to at all. Yet, 6 of the 24 patients within the cohort were such cases. 
Besides a general question about cause(s) we asked who they knew who had or had had TB and their opinion about the cause(s) in each case. All respondents were familiar with at least a few cases, their own neighbors in particular. With rare exceptions the replies can be summed up in: "They had this disease because a lack of cleanliness, carelessness with their eating habits, and because of drinking a lot of alcohol and smoking." A few added, "... and by staying up late at night." Only one or two spontaneously suggested that the cause was likely to be a transfer from one person to another. Even so, when asked, "Is TB infectious/transmittable between persons?" almost all acknowledged this to be the case.

A transfer, it was said, was possible by sharing food, coughing, sleeping together, and by sitting next to a person with TB. At the same time, the majority happily recognized that contrary to earlier days there was no longer a fear or hesitation to visit, to eat, and to sit together with a TB patient. In older days, it was said, TB patients were "hated" and avoided, some being moved out of the house and some even out of the village. However, this was no longer the case and should not be the case because "nowadays TB is a normal disease." The latter mostly explained as "a curable disease." In the same breath, in response to the question "Did the person isolate him/herself? If so, in what way?" almost everyone reported that the patient did so within his or her own household. Not by staying separate but by not giving his or her jutho (food remains) to others, by sleeping alone, having separate eating utensils and by not sharing clothes with household members. Outside the household and in relation to other people, however, there were few if any restrictions or protective measures. Visiting, it was said, went on as usual and so people would come and sit close to the patient and they would eat together. The only precaution was not to eat the jutho, the food from the patient's plate. There even seemed to be a certain pride in there being no restrictions. A few, however, did express that, while outwardly happy when together with a TB patient, they were not completely at peace.

\section{The household-members}

The interview-guide used in interviewing household members contained some direct questions about cause(s): "What do you think about the cause(s) of TB?", "Why did your household member get 
the disease?" and "Do you think that TB is infectious (transmittable)? Why or why not?"

The replies were many in kind and not easily categorized. Most would start by saying that they did not know the cause(s) but would eventually present not one but several ideas. "Alcohol" was mentioned by a majority but most often not as the sole cause, particularly not in regard to the TB of the family member. "A weak body", as a main or the major cause was stressed by many. This was the case of a mother with a teenage son affected by TB, who explained that he had been weak and thin from birth onwards and this was because he did not eat well. Another mother suggested that maybe the reason for her son's TB was "... because from childhood he had asthma and bleeding from his mouth." Some located "the weakness of the body" to a specific occasion. This was the case of the widow of a man who died while on treatment, she reported, "Just before he got this disease there was a wedding party in the village and at the occasion he drank a lot of alcohol and there was a fight and he was beaten badly, and afterwards he was very sick and also got TB." Yet, another respondent after having proposed "too much alcohol" simply added "... maybe he had also eaten something poisonous." One or two suggested that "having been in India" might have caused the condition.

At the same time, when asked, almost all the respondents, like the neighbors, acknowledged TB to be an infectious disease. This was the situation with a parent who proposed that his son's TB might have come about "... .because he was familiar with a TB patient." Such a straightforward suggestion of a transfer, however, was rare. Having acknowledged TB to be an infectious disease most respondents simply left it at that. And yet, in several of the households/families there had been others with TB. Having acknowledged TB to be infectious a young man in such a household suggested that perhaps the reason for his brother's disease was because the condition was "hereditary" as their mother had earlier had TB. In and through it all, there were many uncertainties.

\section{The patients}

So what about the patients themselves, what did they say? All except one of those formally interviewed, agreed to TB being an infectious 
disease with one respondent restraining the infectiousness "to special seasons." The one who did not agree to TB being infectious was a woman diagnosed with a sputum-smear of $3+$, that is, an infectious case. Again, however, in sharing their own ideas of why they themselves ended up with TB, hardly anyone referred to a transfer and the few who did, in one way or another, did never suggest it as the only factor.

When specifically asked, most patient respondents agreed to having heard that 'germs' (kira/kira aunu) were involved: health workers had mentioned "germs" or they had heard it referred to over the radio, and so on. They themselves were absolutely willing to include germs as a cause but the idea and concept obviously was not uppermost in their thinking.

When purposely asked about the main cause, the most common response was a direct or an indirect reference to "a weak body." Asked to elaborate upon the subject, most would say that their body was weak because a lack of proper food, having worked too hard, alcohol, and so on. Again, some referred to or added specific circumstances. This was the case of a man who said, "While going near the stream, I might have been attacked by a God or while sleeping I had a wrong posture and got the chest pain." Another respondent suggested, "I don't really know, but I think it might have been a river God." And, yet another proposed, "Maybe because a dirty environment and by eating dirty things."

To the question: "While on treatment, did you believe that you were contagious, i.e. that you could transmit the disease to others. And if so how/by what route?" an older respondent, a pulmonary sputumsmear positive case did not give an answer but the rest of the adults, also the non-infectious cases (except one) testified to believing themselves to be or having been contagious. And, in most of the households, also in those with non-infectious patients, precautions against a domestic transfer had been taken and had most often been instituted by the patient him- or herself. Moreover, such safety measures were in most cases upheld for the whole treatment period and in some cases even longer. 


\section{Perceived Causes of Tuberculosis in the Second Study, 2012/13}

During a month and an half, besides talks and interviews with the TB patients there were observations, discussions, and formal interviews with household members, neighbors and other residents. Agriculture was continuously the main occupation but the number and percentage of people employed outside had risen. Next to Solubang a tarmac road had been built which made it easier for the residents to reach the district headquarters and other localities within and outside the district. The number of smokers and heavy drinkers within the village was reported to have increased because there was more money around and the tarmac road offered easier access to larger towns and cities.

In 2012, there were approximately as many practicing traditional healers as seven years earlier. They were routinely consulted but perhaps not as persistently as previously. Government health services were, as earlier, accessible and thought well of. The Health Post had been upgraded to a Primary Health Centre (PHC). Even so, as before, in most cases the government health facilities were not the first port of call, not even when TB was a suspected possibility. The government health services were said to be good in treating TB but not in diagnosing the condition. Meanwhile, private pharmacies in the nearby district headquarters had multiplied and attracted a steadily growing number of patients. A few TB patients consulted traditional healers parallel to the government's anti-TB treatment, but mostly so for additional ailments.

\section{The previous cohort}

In between 2005-2012, four patients of the first cohort had died. According to family members, TB or the aftermath of TB was the major reason for three of the four deaths. In 2005, with one exception, the guardians but not the children diagnosed with 'ChildTB' ( $n=6$ ) had been interviewed. In 2012, the remaining five were older, contacted and interviewed. In 2012, they all testified to no further problems because of the TB. As to the cause(s) of their TB, one said that she did not know but added that in the village it was not uncommon for children to have TB. Another proposed that it was most likely from her own body. Two suggested that their fathers had worked in India and maybe had brought the disease from there (their 
fathers had not had TB) and the fifth said, "I think it was because of my leg." She had had a bad fall which later resulted in an amputation below the knee. A month after the amputation, shortly before the 2005 interviews, she had been diagnosed with TB.

Two of the patients had had a relapse. One of them, a rather young man from a comparatively well-to-do family, was on treatment during the interviews in 2005. Quite soon after having been declared cured, he started to have similar symptoms as earlier. When informed that it was likely to be a relapse, he set out to India for a confirmation and "better treatment." In 2012, when asked "why a relapse?" he replied, "I have a drinking and tobacco chewing habit, it might have been because of that", and added, "I had a drinking and tobacco habit before and after both treatments but during the treatments I stopped." The second case, a woman in her thirties, also related her relapse to drinking and tobacco.

In 2012, the remaining patients of the 2005 cohort were asked how they presently, that is, seven years later, perceived the cause(s) of their disease. The suggestions of 2012 were not always the same as those proposed in 2005. Had we pinpointed the variances (which we did not) the respondents were likely to have suggested that the present suggestions did not necessarily rule out the earlier ones and vice versa.

In 2012, we asked if, looking back, they thought that something could have been done to prevent them from getting the disease. One of the previous Child-TB cases said, “...perhaps if I had been vaccinated”, the rest said, "No", even those who suggested that drinking and smoking had been a main or the main cause of their TB.

\section{The new cohort}

In between 2005 to 2012/13, 15 Solubang residents were locally registered as TB patients, 10 males and 5 females. Two-thirds were registered as pulmonary cases with half diagnosed as sputum-smear positive. This compared to 24 cases, or rather 22 locally registered cases, with half sputum-smear positive in the preceding seven years. The numbers, however, are not altogether comparable because the borders of the village had changed somewhat. Moreover, rumors had it that, in contrast to earlier, some Solubang TB patients, had, 
on purpose, got their treatment outside the district and one or two even outside the country. Even so, epidemiologically there seemed to have been a slight improvement, which was further indicated by only one of those locally registered being a Child-TB case.

More than half of the patients of the new cohort had a family member or a next-door neighbor previously affected by TB. When asked if family members had been for check-ups or not, the mother of a highly infectious youngster spontaneously replied, "We haven't been sick, so why should we have had a check-up?"

In the 2012/13 cohort three had died before we re-entered the scene. One of them, a man in his sixties, had had a relapse. He died shortly before completing the second round of treatment. His widow had left for another village but the neighbors ascribed his death to "too much alcohol before, between, and during the treatments." Another patient, a woman in her mid-forties, had died shortly after the diagnosis. At the time of registration her weight was $32 \mathrm{~kg}$. The common explanation for her death was that she was not treated in time. The third who had died was an older woman. Her husband was among the patients of the previous cohort. He was the one who suggested TB to be a seasonal infectious disease. In 2005, his wife had been interviewed and at that time she said, "I don't know the causes of the TB disease. Maybe the disease depends upon the state of our health. There is no surety, later we might also get this disease." In 2013, when asked about the causes of his wife's TB her husband said, "At home I had TB and in my neighborhood there were and are people with TB, so it might have been transmitted to her from someone." He further reported that his wife had been well after the TB treatment but later got stomach problems and had died from her stomach problems.

\section{The neighbours}

When asked about the causes of TB in general, there was a wide assortment of suggestions. As previously, however, most did not spontaneously mention the possibility of a transfer. Even so, when specifically asked about the possibility of TB being infectious, most agreed to this being the case, this time, it seemed, with a greater conviction than in 2005. When asked to illustrate such a process, one neighbor replied, "Some persons got TB from their neighbors, some 
while working in India, and some when working in the hospital." Another man said, "Many TB patients in this village didn't keep themselves separate from their family members and were not very careful about their disease, that's why we have had such problems." He added, "If one is careful about one's diet, one is less likely to get TB, but some have hereditary TB." Yet another respondent said, "The adults might get this disease from others but there are also children with this disease. I don't know why or how."

In regard to the causes of TB in identified individual cases several ideas were on offer. The most common, in no specific order were: drinking too much alcohol; lack of food; hereditary; bad/unclean food and water; cigarettes/chewing-tobacco; transfers by sharing food and bed with a patient; from the person's own body; and many go to India to work and they bring this disease from there. Again, there were many 'hola' ('maybes'), that is: all within a framework of uncertainty. Thus, a large number of possible/assumed causes were presented with few firm convictions except that alcohol, a weak body, and transmission were likely to be involved, sometimes all three, sometimes only one or two of them.

Unlike in 2005, it was quite often suggested that all TB cases might not be locally known as some concealed. The main reason was said to be that TB, as a disease, was associated with a lack of personal hygiene and too much alcohol and smoking. Those affected did not want others to think poorly of them and thus they concealed. Concurrently, contrary to seven years earlier, some respondents mentioned that there were those who avoided TB patients.

\section{The household-members}

Again, there were several suggestions offered about the cause (s) of TB in general and also in relation to the TB of the family member. The mother of a daughter diagnosed as a skin TB case began by saying that she really did not know about the cause(s) of TB in general. About her daughter's TB she said, "Maybe typhoid made her weak and this weakness caused her TB." A middle-aged man with infectious TB said, "What I have understood is that this disease develops from the person's own body." His brother said the same. The father of the only Child-TB case in the cohort, a boy of two and an half years of age at the time of the diagnosis, suggested, "He was 
treated for pneumonia for two months, perhaps that is why he got TB." The boy's mother said that she did not really know the cause(s) of TB. About her son's TB, she suggested, "Maybe because he was born one month and a week early." The wife of a man who developed TB while working as an office helper in the district hospital said, "My husband works in the hospital and maybe he got it from there." After a while, she added, "I have heard that this disease transfers from others and sometimes it develops within one's own body." She also told that her husband, a non-infectious case, "....kept himself from others, did not share his food, and slept by himself."

Two-thirds of the patients within the cohort, as mentioned, were diagnosed as non-infectious cases (pulmonary sputumsmear negative and extra-pulmonary cases). Even so, in most TB households, protective safety measures had been installed, almost all on the initiative of the patient. The most common, as in the 2005 cohort, was a separation of eating utensils, of sleeping arrangements, and the person not sharing his food with family members or others. In most cases, again as within the 2005 cohort, the separation measures were upheld for the whole treatment period and in some cases even longer.

In one family two of three sons had ended up with TB. The eldest was included in the 2005 study, the younger in the 2012/13 cohort. In 2013, when asked about the causes of TB in general their mother said, "I don't know. Maybe it comes from one's own body." In connection with the eldest son, diagnosed as an extra-pulmonary case (non-infectious), the health worker had said that the son's TB did not transfer and thus there was no need for precautions. They adhered to the advice. They did the same in the case of the younger son. The younger son, however, unlike his elder brother was a sputum-smear positive case and so was infectious. Meanwhile, the younger son suggested, "Maybe, I got my TB from my elder brother."

\section{The patients}

As in the earlier cohort, the patients presented several likely causes, both in regard to TB in general and to their own TB. Approximately half of the patients suggested that the basic cause of TB was alcohol and cigarettes. At the same time, everyone knew that some TB patients had used neither alcohol nor tobacco. This was evidently the 


\section{Dhaulagiri Journal of Sociology and Anthropology Vol. 10, $2016 \mid 51$}

case of a girl who was only nine when diagnosed. At the time of the interview she was fifteen. To the question about the causes of TB in general and to her own TB in particular, she replied, "I think it might be because of smoking cigarettes or drinking alcohol, or maybe it is a hereditary disease, but there is no one in my family with a chronic disease. Some people also say that it transmits from sharing food. Maybe it came that way!" A minute later, she added, "My cousin had TB, that's why I think it might be hereditary, otherwise why should a child have TB?"

One of the patients, a Solubang man working as an office helper in the district hospital (treated without a clinic card), said that the doctor and the DOTS staff had given health education and told him about the cause of his disease. About the cause he said, "Maybe, the smoke, the dust, and the physical weakness are the causes of this disease." He added, "My fellow villagers have different opinions on this. Some think it is a hereditary disease whereas others think that drinking alcohol and smoking cigarettes are the causes." Somewhat later, he told us, "Yes, it does transfer from one person to another. It transfers through breath and while sneezing. I have kept myself apart from my wife." We understood him to be a pulmonary sputumsmear negative case, that is, a non-infectious case. His next-door neighbor said, "Maybe he got TB because he works in 'the hospital'. I have heard that this disease transfers from others and sometimes it develops from one's own body."

Again as in the previous study, when specifically asked if TB is an infectious disease, almost all agreed to this being so. This was the case of a respondent in his forties, a sputum-smear negative case (non-infectious), who said, "I know that it transfers from one person to another, the others also know because we have all heard this on the radio." To the question about the cause(s) in his own case, he replied, "There might be a cause/causes but I don't know because I am illiterate." This he said a minute after having said, "It depends upon one's body. Like my wife had chest problem and I had TB." A female respondent, a non-medical employee of the nearby PHC, said, "I have heard that if a person drinks alcohol and smokes cigarettes or chews tobacco he/she will have TB." She added, "Yes, I can transfer this disease by my breath and by my spit." She also said, "After my marriage, I learnt that my mother-in-law had had 
TB." She added, "Having learnt that I had TB, I was more worried than embarrassed." She did not say, "...most likely I picked it up at my place of work," a suggestion made, on her behalf, by her nextdoor neighbor. Another patient, a highly infectious case, said, "What I have understood is that this disease develops from a person's own body." He added, "I have TB but they say it doesn't transfer."

There were three registered relapse cases within the cohort, all men. One of them was the man in his sixties, mentioned above, who had died shortly before completing his second round of treatment. The supposed 'relapse' of another man was more likely 'a return after defaulting'. His treatment was started in India but was not completed. Several months later, having arrived in Nepal, he became critically ill, was categorized as a relapse case and re-started on antiTB medicines. In India, his brother before him had been treated for TB. His answer to the question about the causes of TB was, "They say that poverty and alcoholism are the causes." About himself he suggested, "Maybe it transferred to me from my neighbor or from family members." At the end of each interview we asked if there was something the person wanted to ask and he said, "No question, but sometimes I drink and I chew tobacco and I wonder what it will bring about." The third person categorized as a relapse case in the second cohort was a patient interviewed already in 2005, a sputumsmear positive case. At the time of the first interview he was close to the end of his TB treatment. The medicines, he said, had definitely brought about a change for the better. His weight had increased from 53 to $60 \mathrm{~kg}$. The question he posed at the end of that interview was, "If we do treatment regularly will this disease get fully cured? Will it ever emerge again?" Half a year after having been declared cured, again he had severe chest pains. "I went to the hospital for a checkup but they could not tell what was wrong and therefore I went to India where my family is." Before that he had tried the dhami/ jhankri, an astrologer, and had performed a number of religious rituals. In India he had some costly examinations and underwent more than one type of treatment. Having returned to Nepal, he was registered as a relapse case and was re-started on treatment. He, however, defaulted. "I went to a vaidhya (herbal healer)," he said. "The vaidhya told me that if I drink one glass of alcohol per day for eight days I will get well. Eight days later, I revisited the vaidhya and this time he advised me to drink two glasses of alcohol a day. 
I followed his instructions and I got well!" His elder brother told, "While on government treatment, both times, he stopped drinking and stopped chewing tobacco. But now he chews tobacco and drinks two glasses of alcohol per day." As to the reason for his relapse, the patient suggested, "Because of being politically active, I didn't get to eat and sleep properly, that's why I had a relapse. I also wasn't careful about my food." His brother said, "Because it is a contagious disease and my brother, being a political party worker, had to spend much time with a lot of people, perhaps he got the disease from other people." He also said, "Yes, in the house he didn't sit close to us and he had his own eating utensils and slept alone, but only at home." He agreed to his brother's health presently being good but added, "He is still coughing."

\section{Discussions and Reflection on Local Explanatory Model and Biomedicine}

The most outstanding feature in the ethnographic data is the great number of diverse causes suggested and the circumstance of the same person often proposing several causes, some of which, at least at first sight, appear to be quite contrary to one another. In addition, what is suggested at one time is not necessarily the same at another occasion. These findings are in line with Kleinman's suggestion (1980) that lay EMs are likely to be idiosyncratic and changeable, with Young's findings of fragmentary explanations borrowed from multiple sources, and with Helman's suggestion (2007) that lay theories of illness etiology tend to be multi-causal. The documented plurality and the diversity of suggestions are obviously part of the local explanatory model (Subedi, 2002).

Various novel ideas have been picked up from radio messages, local health workers, and other sources but often without a clear understanding and seemingly most often without previous beliefs being disregarded and discarded. Hence, whereas the western model declares TB to be an infectious disease caused by Mycobacterium Tuberculosis only, the Solubang thinking is wider and embraces a large number of possible causes: some traditional, some more contemporary. 
A good portion of the most frequently suggested causes overlap with socio-biomedical reasoning of factors of importance for the development of the disease: a weak body; use of excessive alcohol and smoking; poverty; lack of proper food. In the biomedical model, however, such features are not causal agents but conditions likely to compromise the immune system which gives the TB bacilli a chance to thrive and active TB to develop. Thus, that which superficially appears to be common ground is not really so.

In a similar fashion, thoughts and ideas of what constitutes the disease are at a variance. To the biomedically trained person, TB is the proliferation of the TB bacilli within the patient's body. To the Solubang villagers, as to most Nepalis, 'tibi' is what is there to observe, the outward signs, such as the persistent coughing, the weakness, the lack of appetite, and so on. Even so, when suggesting the possible cause(s) the focus is not on the symptoms per se but on the person and his/her life circumstances. In connection with the start of anti-TB treatment, Solubang patients are told to abstain from alcohol and tobacco while on treatment and to eat nutritious food. Most Nepali patients do not ask questions in health care situations and the mere fact of being told, "Do not drink alcohol!", "No tobacco!" and "Eat nutritious food!" has seemingly often been understood to mean that alcohol drinking, tobacco chewing/smoking, and a lack of proper food are major reasons for TB. Such an understanding has most likely been eased by ideas of this kind coinciding with traditional values and attitudes.

At the same time, everyone was aware that not everyone drinking and smoking in excess ended up with TB. Asked, "why not, i.e. if too much drinking and smoking is the cause of TB?", most respondents replied that they did not know, while some suggested that most likely other matters or conditions were also involved. The reverse situation, that some persons not using alcohol and tobacco got TB, was, as pointed out in the text, also confusing and prompted additional explanations.

To the Solubang villagers, poverty signified exhausting work under difficult circumstances. The latter included lack of food, not enough rest and financial insecurity, all of which easily results in a weak body. Moreover, it often meant that a family member had to go abroad, 


\section{Dhaulagiri Journal of Sociology and Anthropology Vol. 10, $2016 \mid 55$}

mostly to India, to work which is an altogether stressful situation not conducive to happiness and good health. The suggestion that the cause of a person's TB maybe because "he worked in India", seemingly reflect sentiments and expectations of this kind. It also echoes a common idea of a person's constitution being adjusted to the place he/she belongs and when moved from his/her natural environment the person easily falls ill (Subedi 2001:97). To some, in addition, the country and nation of India represent most things wrong.

The suggestion of TB as a hereditary disease is not about a shared genetic profile. In some interviews the concept referred to a shared fate (Bhagya). Not a blind but an earned fate (Karmic justice) which manifests and manifested itself by members of a family or kinship group being 'attacked' by one and the same disease or by misfortunes in general. In other interviews the expression apparently simply referred to the transmittable nature of $\mathrm{TB}$, that is, to a more mundane process of disease transmission within a family. In yet others, there seemed to be a mixture of the two. "Because of bad Karma", was not a cause spontaneously referred to, albeit sometimes obviously lurking in the background. In a similar fashion, in one way or another, there often seemed to be an expectation and a conviction that what had happened could not have been avoided. Thus, fatalism was in the picture, not necessarily as a driving force but as an understanding and explanation.

The commonly expressed idea of TB being "from the person's own body", is not a negation of a transfer capacity but a statement of the disease not being caused by external supernatural forces like evil eyes, offended ghosts, and angry Gods and Goddesses. In the two performed studies, however, TB was rarely suggested to be caused by an active, purposeful intervention of a sensate agent, neither by men nor by from within the shamanistic sphere nor by any of the major gods of the Hindu pantheon. Parallel to the proposed causes there were uncertainties. The latter demonstrated in what was said but also in gesticulations: the many "hola", 'maybes' and the frequent use of the Nepali gesture for "perhaps, who knows?." Part of the expressed uncertainty is likely to stem from an awareness of ideas and beliefs of old being questioned in the modern world but also to a common acceptance of reality being too complex to fathom. 
In addition to expressed uncertainties there were also "I don't know" or "I really don't know." Such a response was more frequently given by women than men, a circumstance not altogether surprising as women were expected to know less than men and also tended to be more restricted in their contact with the outside world. However, as mentioned, having declared a lack of knowledge most respondents, even the women, proceeded to present at least some ideas. On the other hand, a few did not and particularly not in regard to individual cases, household-members in particular. Whereas some of the "I don't know" replies were likely to be genuine, others might have been a strategy to avoid embarrassing suggestions. The latter is deduced from the fact that, in several of the families of those who said they did not know, there was or had been a TB patient and thus most likely some thoughts and ideas about what had brought about the disease. At the same time, however, concerted discussions about the reason/s for the TB in the family had, in several cases, evidently not taken place. The rationale for this might be traced to the notion of the less attention paid to a calamity the better, but also to a culturally imprinted hesitancy to point an accusing finger at someone, particularly at a close relative. A hesitancy of this kind corresponds to members of households with a TB patient often emphasizing that the patient him- or herself was the one to initiate the safety measures within the household. For the initiative to have come from someone else would have shamed the patient.

When directly asked, everyone, or almost everyone readily agreed to TB being a contagious disease yet spontaneously a transfer was hardly ever mentioned as an assumed cause. The latter may in part be connected with the previously mentioned unwillingness to point a finger at someone. Mostly, however, it seemed to reflect a situation of transmission in the biomedical sense being more head knowledge than a matter influencing perceptions, more so in 2005 than in 2012/13.

Within the homes, the precautionary measures taken coincided with traditionally expected routes for a transfer of ritual pollution: the sharing of what touches the mouth - the eating utensils; that which is next to the skin - used clothes; body to body - sleeping together (sexual intercourse definitely so); and the partaking of what has been on another person's plate (see below). Within traditional Nepali 
thinking each of these routes can be used positively to create equality and unity (shared pollution) but also negatively in an intended or unintended transfer of pollution. The same routes were obviously also believed to be crucial in a possible transfer of TB and thus the safety measures installed within the homes. At the same time, the charted routes were hardly relevant in the context of visitors' contact with a TB affected person inside or outside the home.

Concurrently, the biomedically proposed greatest danger, that is, the exposure and the inhalation of air-born droplets containing TB bacteria, was rarely in the calculation neither in regard to household members nor to outsiders. And yet, there were some remarks, not many but some, and again more so in 2012/13 than in 2005, about TB being transferred through "breathing", "sneezing", and "coughing." Rarely, if ever, however, were such suggestions linked with precautionary behavior.

The separation measures carried out in regard to household members after the diagnosis might have had psychologically positive effects but are not likely to make or to have made an epidemiological difference, as most transmissions within a household are likely to take place before diagnosis. Thus, post-diagnosis precautionary measures, according to the biomedical understanding, are primarily to protect causal contacts and so quite opposite to that which was and is taking place in Solubang and in large parts of Nepal. Moreover, the idea of the need for separate utensils, food, water, and clothes within the household does not square with the biomedical notion of human TB not being harmful from surfaces (Lamsal et al 2009:26). The precaution of not sharing a bed, including not having sexual intercourse, is more to the point, not because of the physical closeness per se but because of the short breathing distance in often badly ventilated sleeping quarters.

According to Ayurvedic principles, besides a general exchange with the immediate surroundings and transfers by touch, a human body is endowed with 'gates'. The mouth is a major one. It is common to express goodwill by distributing choice food items from one's plate. Concurrently, to partake of a person's food leftovers is to share a person's ritual pollution. In Solubang as in most of Nepal, to eat the jutho of a disease-polluted person was and is not acceptable, 
neither in relation to family member nor to outsiders. Thus in the ethnographic data from Solubang it is rarely mentioned as a likely route or cause. When asked why food leftovers are perceived as particularly dangerous the common reply was that whatever has been on a person's plate is likely to be soiled by the saliva of that person.

From a traditional point of view saliva is discharged, concentrated, ritual pollution, whereas from a biomedical point of view the same is germ-infested secretion. In regard to the latter, the biomedical discourse, as mentioned, suggests that human TB bacilli are not transferred from surfaces, i.e. not from saliva, leftover food, and water but only through air-born droplets, that is, not by eating and/ or touching but by inhalation only. Even so, in both models, the mouth is a key gate for the transfer of the disease (exhalation) but quite differently so.

The situation of precautionary initiatives within TB households being upheld far longer than needed, that is, long after a patient is noninfectious, is at least in part the result of health workers not putting all that much effort into explaining the ins and outs of the disease. There is no need for separation measures in extra-pulmonary cases and in initially infectious cases, not after a sputum conversion. The latter is commonly determined by routine microscopic examination of sputum after the first two months of medication. In part, however, the prolongation of the safety measures within the households was also prompted by the 'mystery' of why medicines are needed many months after the disappearance of signs and symptoms.

The one thing hammered in by the health workers is the absolute 'must' to complete the full course of anti-TB medicines and the patients comply, partly because they are aware of their own incomplete understanding of the disease and partly not to kindle the anger of the health workers. Moreover, the strict order to continue with daily medicines, even after the regaining of health, must mean, it is thought, that there are bits and pieces left of the disease and thus it is reasoned, most likely also a need for continuous safety measures for at least as long as the treatment is going on and, according to some, the longer the better. 


\section{Conclusion}

In the past, TB was a fatal and an utterly feared disease. The conditions denoted 'khapte', 'sukenash' and later 'kshayarog' were likely to be pulmonary TB in advanced stages and, as such, ending in death whatever the interventions, irrespective of the curative efforts of dhamis/jhankris and vaidhyas. Many respondents' strong emphasis on TB no longer being "a greatly feared disease", or "no longer a fatal disease" clearly shows that the EMs tend to be 'idiosyncratic and changeable' (Kleinman, 1980). Compared to 2005, people were better aware on the need for timely treatment in 2012. The arrival of the biomedical anti-TB medicines has changed the situation for the better and is widely recognized to have done so. In fact, the empirical data bear witness to most patients being 'happy' to learn that their condition is TB because they know that it is a treatable disease and that the medication is free and easily available. Even so, it is far from an easy ride. Many are dreadfully sick before being properly diagnosed, the treatment period is long, there are economic losses and expenses and there is the negative image.

The Solubang ethnography shows that assumed and suggested causes of TB are multiple but most often within a framework of great uncertainty. Part of the explanation to the many diverse suggestions is likely found in the rather fluid situation, including alterations in health care services on offer, the addition of biomedicine in particular. After a TB diagnosis, the common understanding is that the best and, most likely the only effective treatment, is within the biomedical sector and this irrespective of assumed cause(s). Still, in order to provide as good a support as possible, those health workers who are involved would do well to invest in understanding the patients' perceptions of the causes and subsequent behavior. The Solubang study shows that perception of causes of TB and its prevalence have not changed drastically over the last years. Parallel to this, the mortality rate has not decreased at the speed hoped for.

\section{Acknowledgements}

Ethical approval for this research was taken from Nepal Health Research Council. We especially thank the anonymous reviewers for the constructive feedback and comments which greatly helped 
to shape the paper in this form. The fieldwork was made possible by generous grants from the Swedish Research Council and the University of Gothenburg, Sweden.

\section{References}

Baral, S.C., Karki, D.K., and Newell, J.N. (2007). Causes of Stigma and Discrimination Associated with Tuberculosis in Nepal: A Qualitative study. BioMed Central Public Health, 7:211. http://dx.doi.org/10.1186/1471-2458-7-211

Baral, S.C. and BC, R.K. (2011). Knowledge, Attitude and Practice (KAP) on Tuberculosis (TB) and Co-infection of TB and $H I V$ in Nepal. Kathmandu: Health Research and Social Development Forum (HERD).

Bhatt, C.P., Bhatt A.B. and Shrestha B. (2009). Nepalese People's knowledge about Tuberculosis. SAARC Journal of Tuberculosis, Lung Diseases and HIV/AIDS, 6 (2), 31-37.

Bhatt, C.P., Bhatt A.B. and Shrestha B. (2010). Knowledge of Tuberculosis Treatment - A survey among tuberculosis patients in (DOTS) Program in Nepal. SAARC Journal of Tuberculosis, Lung Diseases and HIV/AIDS, 7(2),10-14.

Burke, S.D.A. (2011). Tuberculosis: Past and Present. Reviews in Anthropology, 40(1), 27-52.

http://dx.doi.org/10.1080/00938157.2011.547754

Dheda, K., Schwander, S.K., Zhu, B., van Zyl-Smit R.N., Zhang Y. (2010). The Immunology of Tuberculosis: From bench to bedside. Respirology 15(3), 433-450.

http://dx.doi.org/10.1111/j.1440-1843.2010.01739.x

Engelbrektsson, U. B. (2012). Challenged Lives. A Medical Anthropological Study of Leprosy in Nepal. Gothenburg: Acta Universitatis Gothoburgensis. University of Gothenburg.

Evans-Pritchard, E.E. (1937). Witchcraft, Oracles and Magic among the Azande. 1960 edition. Oxford: The Clarendon Press.

Foster, G.M. and Anderson, B.G. (1978). Medical Anthropology. New York: John Wiley and Sons.

Harper, I. (2006). Anthropology, DOTS and Understanding Tuberculosis in Nepal. J.Biosoc. Sci. 38, 57-67. http://dx.doi.org/10.1017/S0021932005000982 
Dhaulagiri Journal of Sociology and Anthropology Vol. 10, $2016 \mid 61$

Hatherall, B. (2009). Understanding TB-related Stigma in Asia. Kathmandu: Health Research and Development Forum (HERD), Nepal.

Helman, C. (2007). Culture, Health and Illness. 5th edition. London: Hodder Arnold.

HERD (2016). Getting United to End TB - Celebrating World TB Day 2016 (Special Series). Kathmandu: HERD.

Kirwan, D.E. et al. (2009). The social reality of migrant men with tuberculosis in Kathmandu: implications for DOT in practice. In Tropical Medicine and International Health, Vol. 14, 1442-1447.

http://dx.doi.org/10.1111/j.1365-3156.2009.02405.x

Kleinman, A. (1980). Patients and Healers in the Context of Culture. Berkley: University of California Press.

Salzberger, R. C. (1976). Cancer: Assumptions and Reality concerning Delay, Ignorance and Fear. In J. B. Loudon, ed. Social anthropology and Medicine pp. 150-189. New York: Academic Press.

Smith, I. (1999). Stop TB: Is DOTS the answer. Ind. J. Tub., 46, 81-90.

Subedi, M.S. (2001). Medical Anthropology of Nepal. Kathmandu: Udaya Books.

Subedi, M. S. (2002). Explanatory Models of Food, Health and Illness Ideology in Newar Town of Kirtipur. In R.P. Chaudhary, B. Subedi, T. Aase and O.Vetas eds. Vegetation and Society, pp 228-239. Tribhuvan University, Nepal and University of Bergen, Norway.

Subedi, M. S. (2003). Healer Choice in Medically Pluralistic Cultural Settings: An Overview of Nepali Medical Pluralism. Occasional Papers in Sociology and Anthropology, 8, 130158.

Subedi, M. (2011). Illness Causation and Interpretation in a Newar Town. Dhaulagiri Journal of Sociology and Anthropology, $5,101-120$.

Trostle, J.A. (2005). Epidemiology and Culture. Cambridge: Cambridge University Press.

http://dx.doi.org/10.1017/CBO9780511806025

WHO (2014). Global Tuberculosis Report 2014. Geneva: WHO.

WHO (2015). Tuberculosis Control in South-East Asian Region: Annual TB Report 2015. New Delhi: World Health 
Organization, Regional Office for South-East Asia.

Young, A. (1982). The Anthropologies of Illness and Sickness. Annual Review of Anthropology, 11, 257-285.

http://dx.doi.org/10.1146/annurev.an.11.100182.001353

Engelbrektsson, Ulla-Britt ( $\mathrm{PhD}$ in Social Anthropology, 1979) was Lecturer (1972-1998) and Associate Professor (1998-2009) at the University of Gothenburg, Sweden, and between 2010-2014, she served as a member of the University of Gothenburg's Global University Initiative. Ulla-Britt's publications are focused on socio-cultural aspects of infectious diseases especially Tuberculosis and Leprosy. Currently, UllaBritt Engelbrektsson is Planning and Evaluation Officer of the International Nepal Fellowship based in Surkhet, Nepal.

Email: ulla-britt.engelbrektsson@inf.org

Subedi, Madhusudan is Professor and associated to the Central Department of Sociology, Tribhuvan University, Nepal. For last 20 years, Subedi has focused on 'social determinants of health', 'women and health', 'pharmaceuticals', 'infectious diseases', 'caste system', 'informal networking', 'qualitative research methods' and 'polity and social transformation' in Nepal.

Email: madhusudansubedi@gmail.com 